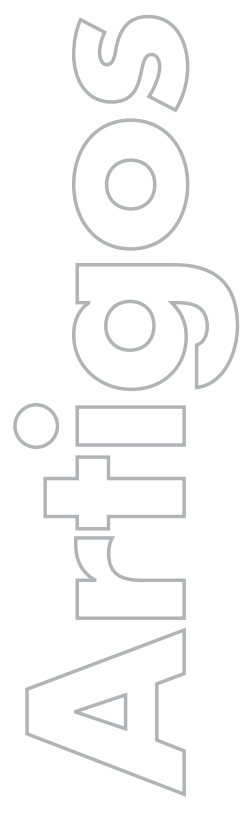

\title{
Índices de vegetação e competição entre cidades
}

\author{
Mariane Félix da Rocha \\ UFPR
}

João Carlos Nucci

UFPR

\section{revista}

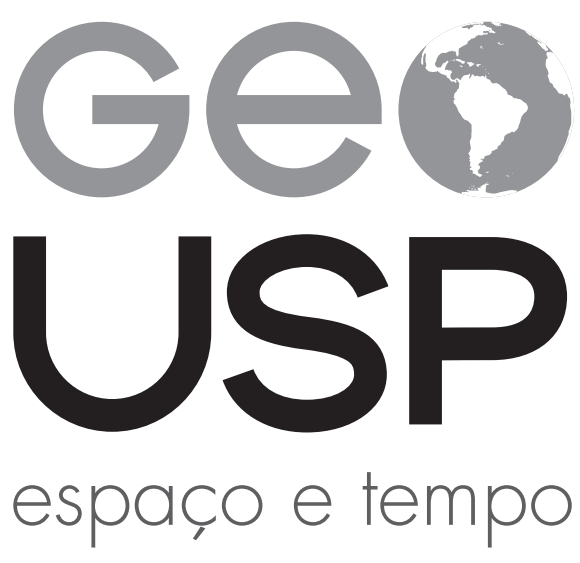

Volume $22 \cdot n^{\circ} 3$ (2018)
Como citar este artigo:

ROCHA, M. F; NUCCI, J. C. Índices de vegetação e competição entre cidades. Geousp - Espaço e Tempo (Online), v. 22, n. 3, p. 641-655, dez. 2018. ISSN 2179-0892.

Disponível em: <https://www.revistas.usp.br/geousp/article/view/133554>. doi: http://dx.doi.org/10.11606/issn.21790892.geousp.2018.133554.

\section{(C) $(1) \Theta$}

Este artigo está licenciado sob a Creative Commons Attribution 4.0 License. 


\title{
Índices de vegetação e competição entre cidades ${ }^{*}$
}

\section{Resumo}

Muitas cidades exaltam seus índices de áreas verdes ou de cobertura vegetal e os comparam com os de outras para provar sua superioridade nesse quesito. Com base nessa constatação, foi escrito este artigo de revisão bibliográfica, com três objetivos principais: discutir a questão dos índices de áreas verdes ou de cobertura vegetal das cidades, verificar a possibilidade de comparação entre os diversos índices de cobertura vegetal ou áreas verdes de algumas cidades brasileiras e buscar uma resposta para a necessidade de cidades competirem entre si. Obtiveram-se as seguintes respostas: a utilidade dos índices de vegetação depende da clareza de sua elaboração e da realidade a que se pretende aplicá-los; na maioria das vezes, as prefeituras divergem quanto à conceituação e aos materiais e métodos de medição da vegetação utilizados, impossibilitando a comparação; a necessidade de competição entre as cidades se deve à imprescindibilidade de estas se destacarem nos quesitos sustentabilidade e qualidade de vida para atrair investimentos.

Palavras-chave: Índices. Área Verde. Cobertura vegetal. Competição. Cidades.

\section{Vegetation indexes and competitiveness among cities}

\begin{abstract}
Many cities exalts their green areas or vegetation cover indexes and compare themselves with other cities to prove their superiority in this matter. Based on this observation, this bibliographical review was written with three main objectives: to discuss the question of the green areas or vegetation cover indexes of the cities; to compare the various vegetation cover or green areas indexes of some Brazilian cities; and to seek a response to the cities' requirement to compete with each other. Regarding these questions, the findings of our research shows us some possible answers. Firstly, we found out that the use
\end{abstract}

1 * CNPq: Bolsa Produtividade em Pesquisa-PQ-2014. Processo: 306023/2014-8. Capes: Bolsa País de Mestrado. Processo: 1497596. 
of vegetation indexes depends on the clarity of their design and the reality where they are supposed to be applied. Secondly, we could say that, in most cases, the city halls differ on the concept and on the materials and methods of measurement of the vegetation used, making it impossible to compare them. Finally, we understood that the need for competition among cities is due to their indispensability to stand out in terms of sustainability and quality of life in order to attract investments.

Keywords: Indexes. Green areas. Vegetation cover. Competition. Cities.

\section{Introdução}

A vegetação no meio urbano traz benefícios tanto ambientais quanto à saúde física e psíquica do homem. Quanto aos benefícios ambientais, a vegetação atua no sentido de estabilizar as superfícies por meio da fixação do solo pelas raízes das plantas; controlar a radiação solar direta; proteger a qualidade da água evitando que poluentes escorram para os rios; fornecer sombra; regular a umidade relativa do ar e do solo; filtrar e redirecionar o vento; estabilizar a temperatura do ar; reduzir a poluição do ar; atenuar o ruído e proporcionar condições à existência da vida selvagem, entre outras funções (Hough, 1998; Mascaró, 1996; Nucci, 2008; Sukopp; Werner, 1991; Woolley, 2003).

Com relação aos benefícios à saúde física e psíquica do homem, destacam-se o estímulo à prática de atividades físicas; o favorecimento das relações de amizade e sociabilidade; a redução dos níveis de estresse e alívio da tensão psicológica e a redução do comportamento agressivo e do deficit de atenção em crianças e adolescentes (Park et al., 2010; Woolley, 2003; Younan et al., 2016).

Talvez em função desses benefícios haja tanto interesse em ostentar bons índices de cobertura vegetal ou áreas verdes nas cidades. No Brasil, Curitiba (PR), Goiânia (GO), Campo Grande (MS) e João Pessoa (PB) têm um título de cunho ambiental, a saber, respectivamente: a cidade mais verde da América Latina (Curitiba [...], 2010); a cidade mais arborizada do Brasil e a segunda mais arborizada do mundo (Portal do Servidor, 2014); a capital mais arborizada do Brasil (Maymone, 2012); e a segunda cidade mais verde do mundo (Destino [...], 2014). Também a cidade de Maringá (PR) afirma ser uma das cidades mais arborizadas do Brasil, com um índice de $26 \mathrm{~m}^{2}$ de áreas verdes por habitante (Maringá, [s.d.]).

Dada essa necessidade de as cidades se destacarem no quesito quantidade de vegetação no meio urbano frente às outras cidades, esse artigo busca, por meio de revisão bibliográfica, os possíveis motivos para essa competição entre as cidades. Ademais, o artigo discute a questão dos índices de áreas verdes ou de cobertura vegetal, do ponto de vista de sua aplicabilidade, limites de abrangência e indicação de valores mínimos a serem atingidos, bem como analisa a forma como as prefeituras medem e divulgam os dados de áreas verdes ou cobertura vegetal de seus territórios, verificando se é possível a comparação entre elas com base nesses dados. 


\section{Índices de áreas verdes}

O termo cobertura vegetal pode ser entendido como "projeção do verde em cartas planimétricas e pode ser identificada por meio de fotografias aéreas, sem auxílio de esteroscopia" (Cavalheiro et al., 1999, p. 7). Segundo os autores, essa definição inclui a vegetação encontrada também nos acompanhamentos viários.

As áreas verdes, por sua vez, podem ser conceituadas como um tipo especial de espaço livre de construção, isto é, espaços urbanos ao ar livre destinados ao lazer nas horas de ócio, nas quais predomina a vegetação (Cavalheiro et al., 1999).

Tão vasta quanto as formas de conceituar a vegetação encontrada nas cidades são as formas de medi-la: o índice de cobertura vegetal, por exemplo, é encontrado pela quantificação da cobertura vegetal em $\mathrm{m}^{2}$ ou $\mathrm{km}^{2}$ de uma área e a porcentagem que ela ocupa no total dessa área (Nucci; Cavalheiro, 1999); o índice de áreas verdes por habitante pode ser encontrado pela divisão da quantidade de espaços livres de uso público em $\mathrm{km}^{2}$ ou $\mathrm{m}^{2}$ pelo número de habitantes de uma cidade (Toledo; Santos, 2009), entre outros.

Alguns autores e órgãos sugerem índices mínimos de cobertura vegetal, como Oke (19732 apud Lombardo, 1985), que sugere o valor mínimo de 30\% de cobertura vegetal nas áreas urbanas para que haja um adequado balanço térmico. Outros índices descritos na literatura envolvem a demografia, relacionando a quantidade de áreas verdes presentes na cidade com o número de habitantes.

O relatório Perspectivas del medio ambiente: América Latina y el Caribe, do Programa das Nações Unidas para o Meio Ambiente (Pnuma, 2010, p. 156) afirma que a Organização Mundial da Saúde (OMS) recomenda um índice entre $9 \mathrm{~m}^{2}$ e $11 \mathrm{~m}^{2}$ de área verde por habitante, mas não menciona o documento da OMS em que estaria essa informação.

Um índice com valor próximo a esse, de $12 \mathrm{~m}^{2}$ de área verde por habitante, teria sido recomendado pela Organização das Nações Unidas (ONU), mas Cavalheiro (1982) obteve por carta uma resposta da própria $\mathrm{NU}$ em que afirmava desconhecer esse índice. Nucci (2008) aponta que, na Carta de Londrina e Ibiporã, de 1996, da Sociedade Brasileira de Arborização Urbana (Sbau), está a recomendação de um índice mínimo de $15 \mathrm{~m}^{2}$ de áreas verdes públicas destinadas à recreação por habitante. A Associação Nacional de Recreação dos EUA recomenda um índice de áreas verdes entre $28 \mathrm{~m}^{2}$ a $40 \mathrm{~m}^{2}$ por habitante (Martins Júnior, 1996).

Não é difícil, portanto, encontrar na literatura recomendações de índices mínimos de cobertura vegetal ou de quantidade de áreas verdes por habitante. Difícil é descobrir como se chegaram a esses números, com base em quais critérios, com que metodologia, para quais cidades e em que período.

Os índices e indicadores são instrumentos científicos que permitem descrever as características de um fenômeno ou avaliar seu comportamento ao longo do espaço e tempo (Pnuma, 2003). Têm a função de fornecer informações para a produção de diagnósticos e avaliações que orientem o planejamento de políticas públicas, além de apresentarem fenômenos complexos de forma simplificada e favorecer a elaboração de séries históricas com os dados coletados (Sepe; Gomes, 2008).

2 OKE, T. R. City size and the urban heat island: Conference on Urban Environment and Second Conference on Biometeorology. American Meteorological Society, Philadelphia, p. 144-146, 1972. Em Lombardo (1985), não foi encontrada uma obra referente a Oke (1973), sendo essa de 1972 a mais próxima cronologicamente. 
A elaboração desses índices com a temática ambiental, todavia, pode se revelar uma tarefa complexa. A busca da equipe da Secretaria Municipal do Verde e do Meio Ambiente (SVMA) da Prefeitura de São Paulo por um Índice Ambiental ou Indicador Sintético para a cidade com base na metodologia Global Environmental Outlook (GEO) do Pnuma ilustra essa dificuldade. Em 2004, a SVMA dispunha de 83 indicadores desdobrados em 254 variáveis, e desde 2006 vem buscando construir um indicador socioambiental único (Sepe; Gomes, 2008).

A escolha de um indicador socioambiental para a cidade de São Paulo em vez de um propriamente ambiental refere-se à noção de que, no meio urbano, os processos ambientais não podem se dissociar dos processos econômicos e sociais e a opção por um indicador sintético se dá pelo fato de facilitar a disseminação e o debate de informações complexas por meio de um índice único (Sepe; Gomes, 2008).

Ainda segundo Sepe e Gomes (2008), o uso de indicadores sintéticos, no entanto, pode resultar em uma simplificação excessiva da realidade, pouco contribuindo para a formulação de políticas públicas. Por exemplo, a formulação de um indicador socioambiental sintético para a cidade de São Paulo mascararia a existência de realidades intraurbanas muito distintas entre os 96 distritos paulistanos, além da possibilidade de incluir na mesma categoria ou classificar com o mesmo valor distritos com características diferentes (Quadro 1).

\section{Quadro 1 - Simulação da condição socioambiental de dois distritos}

\begin{tabular}{|l|l|l|l|}
\hline distrito & condições ambientais & condições sociais & $\begin{array}{l}\text { condição } \\
\text { socioambiental } \\
\text { (média) }\end{array}$ \\
\hline distrito 1 & $\begin{array}{l}\text { alta preservação ambiental } \\
\text { valor recebido: } 100\end{array}$ & $\begin{array}{l}\text { nenhum esgotamento sanitário } \\
\text { valor recebido: 0 }\end{array}$ & valor: 50 \\
\hline distrito 2 & $\begin{array}{l}\text { baixa preservação ambiental } \\
\text { valor recebido: } 10\end{array}$ & $\begin{array}{l}90 \% \text { dos domicílios com } \\
\text { esgotamento adequado } \\
\text { valor recebido: } 90\end{array}$ & valor: 50 \\
\hline
\end{tabular}

fonte: Sepe e Gomes (2008).

Assim, constatou-se a impossibilidade de se adotar um índice único para a cidade de São Paulo, optando-se por um conjunto de indicadores sintéticos e dividindo a análise em quatro tipologias de distritos, sendo possível a comparação apenas entre os distritos de um mesmo grupo, com condições socioambientais minimamente similares (Sepe; Gomes, 2008).

Dada a dificuldade de se analisar o conjunto de distritos de uma mesma cidade com base em um indicador criado para esse fim, é possível avaliar a insensatez de se tentar comparar cidades diferentes, ambiental, socioeconômica e historicamente, com base em um indicador cujos critérios de elaboração são desconhecidos ou que foi criado para mensurar a realidade de outros países, uma vez que cada cidade tem um potencial próprio em relação à quantidade de área verde, em função de suas características geográficas, culturais e políticas (Martins Júnior, 1996). Esse problema, nas palavras de Figueiró (2015, p. 260, grifo nosso) salienta a necessidade de "pensar muito mais em princípios de manejo que sejam capazes de orientar o design ecológico em áreas urbanas do que propriamente no estabelecimento de algum índice impreciso que resulte na comparação do incomparável". 
O trabalho de Rocha (2017) ilustra essa questão da dificuldade de se comparar cidades e elaborar índices. Ao buscar estabelecer um ranking entre as 27 capitais brasileiras, a autora obteve como resultado que Brasília (DF), com 31,83\% de cobertura vegetal, alcançou a primeira posição. Conforme a recomendação de Oke (1973 apud Lombardo, 1985), um índice de 30\% de cobertura vegetal seria indicado para a manutenção de um adequado balanço térmico das áreas urbanas, e apenas uma capital alcançou esse índice, ou seja, Brasilia, no Distrito Federal, pois a segunda posição do ranking, Rio Branco (AC), obteve 27,96\% de cobertura vegetal.

Esses índices propostos por Oke (1973 apud Lombardo, 1985), no entanto, segundo Buccheri Filho e Nucci (2006) foram elaborados para cidades canadenses. De acordo com dados disponibilizados on-line na página Current Results (Osborn, 2016), as dez cidades mais quentes do país apresentaram valores de temperatura média diária máxima anual de 15,3० C a $12,1 \circ \mathrm{C}$, enquanto as cidades brasileiras mais quentes apresentam uma média acima de $18 \circ \mathrm{C}$ em todos os meses (Brasil, 2002).

$\mathrm{Ng}$ et al. (2012) reforçam o pressuposto de que um índice de 30\% seria o recomendado para amenizar as condições climáticas das cidades de clima subtropical úmido. Portanto, para as cidades brasileiras de clima tropical e, consequentemente, mais quentes, o índice mínimo recomendado de cobertura vegetal deveria ser maior, em função de a vegetação contribuir para amenizar o calor (Mascaró, 1996), mas faltam estudos que indiquem parâmetros "ideais" para as cidades brasileiras.

Ao se relativizar os resultados obtidos dessa forma, percebe-se que, se um índice ideal para a maior parte das cidades brasileiras deveria, provavelmente, ser maior que 30\% e, mesmo assim, apenas uma área de estudo do trabalho de Rocha (2017) atingiu esse patamar, as áreas estudadas das capitais apresentaram índices de cobertura vegetal menores do que seria desejável para garantir a funcionalidade da vegetação em suas características climáticas, o que poderia trazer desconforto térmico para seus habitantes.

Além da relação com o conforto térmico, as diferenças climáticas entre as cidades podem também afetar os índices de cobertura vegetal alcançados. Segundo Moura e Nucci (2005), cidades que se desenvolvem onde a evapotranspiração é menor que a precipitação apresentam um potencial para uma maior cobertura vegetal, enquanto cidades situadas em regiões desérticas geralmente apresentam índices menores de cobertura vegetal. Nowak et al. (1996) citam estudos que encontraram de 15 a 55\% de cobertura de copas de árvores em cidades situadas em áreas de florestas contra 0,4 a 26\% em cidades desérticas. Nisso reside a dificuldade de se encontrar um índice "ideal" único de cobertura vegetal para todas as cidades brasileiras, haja vista as diferenças climáticas e biogeográficas existentes entre elas. Sendo assim, as comparações entre as capitais brasileiras em relação à quantidade de cobertura vegetal tornam-se prejudicadas.

Todavia, é possível que seja implantada vegetação também em climas mais secos. Nas cidades situadas no planalto central brasileiro, em que há uma estação chuvosa e uma seca, Gouvêa (2002) indica o plantio de espécies nativas do cerrado e encontradas nas matas de galeria para se constituir microclimas úmidos nos trópicos secos. Para isso, segundo o autor há a necessidade de se instalar esguichos e espelhos d'água para que a vegetação resista à estação seca. 
Em cidades desérticas a necessidade de irrigação para manter a vegetação é ainda maior. As residências em Phoenix, nos EUA, gastam de 45 a $70 \%$ de seu consumo de água em regas de áreas externas, sobretudo de gramados (Martin, 2008). O consumo de água para irrigar a vegetação também é uma preocupação em Las Vegas, cidade situada no deserto de Mojave, nos EUA, que, ao passar por uma crise hídrica, incentivou seus habitantes a tirarem o gramado de seus quintais, que gastam cerca de 73 galões de água por pé quadrado (cerca de $930 \mathrm{~cm}^{2}$ ) por ano, tendo transformado em paisagem desértica cerca de 5,5 milhas (1.424,50 ha) de gramados desde 2001 (Sutter, 2011).

Não obstante a melhora que a vegetação pode implicar no conforto térmico das regiões desérticas, sua implantação demanda um alto consumo d'água, como na cidade de Phoenix, onde, antes da popularização do ar-condicionado (que confinou a população em ambientes fechados), a paisagem urbana fora planejada com gramados e árvores de crescimento rápido para tornar os ambientes externos mais habitáveis pelo sombreamento e aumento da evapotranspiração (Martin, 2008). Algumas cidades desérticas, como Phoenix e Las Vegas, tiveram impactos ambientais e sociais negativos com a construção de reservatórios de água e o desvio das águas de rios para o abastecimento urbano. Outras cidades, como Dubai, no Oriente Médio, dependem da dessalinização da água do mar, processo que tem sido responsável por grande parte das taxas de emissão de $\mathrm{CO}_{2}$ que tornaram os Emirados Árabes Unidos um dos países que mais emitem carbono no mundo, além de gerar uma grande quantidade de detritos que são despejados no oceano e aumentar sua concentração de salinidade (Dubai [...], 2010).

Sobre esse aspecto, Hough (1998) afirma que esse tipo de planejamento que demanda muita energia e recursos não se justifica quando existem alternativas mais baratas e efetivas. No caso das cidades desérticas, é preciso verificar se os gastos com manutenção de vegetação exótica são compensados com os benefícios que ela traz para o meio urbano. Por um lado, em Las Vegas, a vegetação adaptada à seca chega a demandar menos de um quarto da água necessária para a irrigação de gramados (Sutter, 2011); por outro, em Phoenix, casas que são cercadas por gramados são mais frias que aquelas que utilizam plantas adaptadas às condições desérticas (Martin, 2008).

Assim, é preciso ter cautela quando se analisam os índices de cobertura vegetal. As cidades que têm mais vegetação estariam contribuindo mais para a melhoria de suas condições climáticas, se comparadas às que têm menos vegetação, mas, dependendo das espécies escolhidas, podem estar aumentando desnecessariamente os gastos com irrigação e manutenção, e/ou utilizando espécies não tão adequadas para a amenização das temperaturas e aumento da umidade relativa do ar.

Outro problema ocultado pela indicação de índices diz respeito à distribuição da vegetação na cidade. Um índice que represente o conjunto de uma cidade pode esconder desigualdades marcantes entre os bairros.

Q Quadro 2, que reúne alguns estudos sobre a cobertura vegetal de vários bairros de Curitiba (PR), elaborados com a mesma metodologia e materiais semelhantes, traz alguns exemplos dessas desigualdades. Em Curitiba (PR), há bairros desde 12\% de cobertura vegetal (Hauer), (Nucci et al., 2005), a 50,47\% (São Braz) (Dalbem; Nucci, 2006). Assim, pode-se conjecturar que por se tratar de bairros com características diferentes, os mesmos deveriam ter índices ideais de cobertura vegetal também diferentes. 
Quadro 2 - Resultados de outras pesquisas sobre cobertura vegetal

\begin{tabular}{|c|c|c|c|c|}
\hline $\begin{array}{c}\text { bairro } \\
\text { (Curitiba-PR) }\end{array}$ & fonte & foto aérea & $\begin{array}{l}\text { área de estudo } \\
\qquad\left(\mathrm{m}^{2}\right)\end{array}$ & $\begin{array}{c}\text { cobertura } \\
\text { vegetal }(\%)\end{array}$ \\
\hline Centro & Nucci et al. (2003) & $\begin{array}{c}1: 8.000 \\
\text { colorida }(2002)\end{array}$ & 3.293 .790 & 12,56 \\
\hline Hauer & Nucci et al. (2005) & $\begin{array}{l}1: 8.000 \\
\text { colorida } \\
\end{array}$ & 4.021 .000 & $12,00 \%$ \\
\hline Bacacheri & Pivetta et al. (2005) & $\begin{array}{c}\text { 1:8.000 } \\
\text { colorida }(2002)\end{array}$ & 6.980 .000 & $28,90 \%$ \\
\hline Alto da XV & $\begin{array}{l}\text { Buccheri Filho e } \\
\text { Nucci (2006) }\end{array}$ & $\begin{array}{c}1: 8.000 \\
\text { colorida }(2002) \\
\end{array}$ & 1.504 .000 & $16,85 \%$ \\
\hline São Braz & $\begin{array}{l}\text { Dalbem e Nucci } \\
(2006)\end{array}$ & $\begin{array}{c}\text { 1:8.000 } \\
\text { colorida (2002) }\end{array}$ & 5.006 .000 & $50,47 \%$ \\
\hline Santa Felicidade & $\begin{array}{l}\text { Moura e Nucci } \\
(2008)\end{array}$ & $\begin{array}{c}1: 8.000 \\
\text { colorida (2002) }\end{array}$ & 12.349 .329 & $42,29 \%$ \\
\hline
\end{tabular}

fonte: Elaborado pelos autores.

Além da distribuição irregular da vegetação pela cidade, outro dado ocultado pela indicação de índices é a acessibilidade da população a essa vegetação. Ao estudar a floresta urbana de Curitiba (PR) com técnicas de sensoriamento remoto, Grise, Biondi e Araki (2016) constataram que 43,69\% da cidade são cobertos por vegetação, dos quais, no entanto, apenas 8,98\% constituem áreas públicas. Isso indica que a maior parte da vegetação da cidade $(34,70 \%)$ se encontra em espaços de uso privado, geralmente não acessíveis à população em geral.

\section{Índices de áreas verdes segundo as prefeituras}

Devido à variedade de formas de se conceituar e medir o verde urbano, também as prefeituras divergem quanto aos termos, métodos e materiais utilizados em seus levantamentos da vegetação urbana. Lima et al. (1994) constataram que as prefeituras apresentam um enfoque mais pragmático que conceitual, não organizando uma hierarquia entre os termos empregados.

A prefeitura de Curitiba divulgou os resultados de seu último mapeamento, finalizado em dezembro de 2011, no qual obteve que cada habitante da capital paranaense dispunha de 64,5 $\mathrm{m}^{2}$ de área verde. Para chegar a esse resultado, o mapeamento considerou apenas os maciços arbóreos, ou seja, as árvores que, com suas copas e folhas, fecham uma cobertura, com mais de $100 \mathrm{~m}^{2}$, observadas em imagens de resolução espacial de 0,5 m do satélite GeoEye (Índice [...], 2012).

A prefeitura de Porto Alegre destaca que tinha $49 \mathrm{~m}^{2}$ de áreas verdes por habitante em 2006 se se considerarem as áreas verdes municipais, estaduais e federais de seu território, em $\mathrm{m}^{2}$, divididas pela população da época (Porto Alegre, 2006), mas não especifica como foram feitos esses cálculos nem qual foi a conceituação adotada.

O Anuário de 2013 de Natal indica que a capital potiguar, ao mapear sua cobertura vegetal com imagens de resolução espacial de 0,5 m do satélite WorldView-2, com imagens de 2010, tinha uma taxa de cobertura vegetal de 40,41\%. O estudo utilizou as bandas do vermelho e infravermelho próximo, pois são as faixas espectrais que a clorofila das plantas melhor 
refletem, e a classificação dos tipos de vegetação da área foi feita a partir da classificação temática por meio de algoritmos (Hora; Medeiros; Capistrano, 2013). Dessa forma, infere-se que foram mapeados todos os tipos de vegetação de todos os tamanhos.

O mapa de Uso do solo da cidade do Rio de Janeiro, elaborado em 2015 pela Gerência de Cartografia da prefeitura, indicou que 42, $1 \%$ da cidade do Rio de Janeiro estão cobertos por vegetação. $\bigcirc$ mapa contou com 16 classes de uso do solo, divididas em dois grupos, dentro do perímetro urbano: as áreas urbanizadas e as áreas não urbanizadas. Apenas nesta classe estão os usos correspondentes à vegetação, sendo que a Mata (cobertura arbórea e arbustiva) corresponde a 31,4\% da área da cidade, que somada à classe Campo (cobertura gramíneo-lenhosa), que ocupa 10,7\% da cidade, atingem o valor de 42,1\% de cobertura vegetal. $\bigcirc$ mapa foi elaborado, segundo o documento "Critérios de mapeamento" anexo ao mapa, por meio de vistorias em campo e da vetorização das classes de uso e cobertura do solo pela interpretação de ortofotos de 2015 na escala 1:10.000 para as áreas urbanizadas e 1:50.000 para as áreas não urbanizadas, na qual se encontram as classes de vegetação. A área mínima mapeada foi de 1 hectare $\left(10.000 \mathrm{~m}^{2}\right)$ tanto nas áreas urbanizadas quanto nas não urbanizadas (Rio de Janeiro, 2015).

A Prefeitura de São Paulo disponibilizou um arquivo Excel elaborado pela SVMA em seu site no qual relata que cada habitante dispunha de $62,85 \mathrm{~m}^{2}$ de cobertura vegetal, sem, no entanto, especificar a data do levantamento. ${ }^{3}$ A cobertura vegetal foi mapeada com imagens do satélite Landsat-7, com uma resolução espacial de $30 \mathrm{~m}$, e o indicador cobertura vegetal mapeou áreas públicas e particulares com cobertura vegetal de todos os portes (arbóreo, arbustivo e herbáceo), incluindo praças, parques, rotatórias, canteiros, cemitérios, escolas, universidades, áreas vegetadas intralote (particulares), chácaras, sítios, reflorestamentos, Unidades de Conservação e outros (São Paulo, [s.d.]).

Percebe-se, então, que não há uma padronização para a medição da vegetação no meio urbano entre as capitais brasileiras, além de não serem todas as capitais que disponibilizam estudos sobre sua vegetação urbana on-line, o que dificulta comparações entre elas com base nesses dados fornecidos.

Apenas com os dados das cinco capitais analisadas aqui, é possível constatar que qualquer comparação feita com base nesses dados colocaria no mesmo patamar:

- cidades que consideraram apenas os fragmentos arbóreos com outras que consideraram todos os tipos de vegetação, inclusive gramados;

- cidades que abrangeram áreas particulares, públicas e de acompanhamento viário com outras que se limitaram às áreas de parques e praças;

- estudos feitos com imagens de satélites de alta resolução espacial, que permitem maior precisão e detalhamento, com outros que usaram imagens de baixa resolução, que dificultam a interpretação dos elementos mapeados;

- estudos que usaram imagens de satélite com bandas espectrais, que favorecem a visualização da vegetação, com outros que dependem de interpretação visual;

- tamanhos mínimos mapeados que variam de $0,25 \mathrm{~m}^{2}$ a $10.000 \mathrm{~m}^{2}$;

- estudos feitos em épocas diferentes, com até nove anos entre um e outro.

3 Pela população utilizada no cálculo, de 11.181.547 habitantes, deduz-se, segundo informações do Instituto Brasileiro de Geografia e Estatística - IBGE (Brasil, 2016), que a data do levantamento deve corresponder ao período entre 2007, quando a cidade abrigava 10.886.518 pessoas, e 2010, ano em que São Paulo contava com 11.253.503 habitantes. 
Dessa forma, percebe-se que uma comparação entre as capitais analisadas considerando os dados fornecidos pelas prefeituras não seria viável ou justa.

\section{Meio ambiente e competitividade}

A despeito da evidente impossibilidade de comparação entre os resultados obtidos pelas prefeituras, o Plano Diretor de Arborização Urbana de Goiânia (GO) traz a seguinte declaração: Goiânia é a capital de estado com a maior extensão de áreas verdes por habitantes e o maior número de árvores em vias públicas do país, em proporção ao número de habitantes. Essa condição foi comprovada por estudos realizados pelos técnicos da Agência Municipal do Meio Ambiente - AMMA, com base em metodologia amplamente utilizada e o apoio de modernas técnicas de georreferenciamento. [...] Goiânia possui hoje 94 metros quadrados de áreas verdes por habitante [...]. Esse índice é superior também aos $51 \mathrm{~m}^{2} /$ habitante de Curitiba, a capital estadual considerada anteriormente líder nesse ranking (Goiânia, [s.d.], p. 29).

Entretanto, o documento não especifica como foi feito o estudo pela AMMA e também não inclui na relação de obras consultadas o nome desse estudo para consulta. Curitiba (PR), por sua vez, em um vídeo institucional de 2003, intitula-se a "capital ecológica do Brasil", enfatizando a boa qualidade de vida que a capital oferece aos seus habitantes, resultado de um planejamento urbano preocupado com as questões ambientais que trouxe para a cidade, além da coleta seletiva do lixo, dos programas de educação ambiental, da construção de ciclovias e das melhorias no transporte coletivo, o aumento vertiginoso da quantidade de áreas verdes por habitante, dos 0,5 $\mathrm{m}^{2}$ /hab anteriores para os $50 \mathrm{~m}^{2}$ /hab na época retratada no vídeo (Capital Ecológica [...], 2003).

Também em um vídeo institucional, de 2007, João Pessoa (PB) afirma ser uma das cidades mais verdes do mundo, "uma capital pintada de verde pela natureza e pelas mãos de um povo que mantém a cultura de plantar árvores nas ruas e quintais, para colher bons ventos" (João Pessoa, 2007).

Uma provável explicação para essa excessiva autopromoção das cidades em torno da quantidade de vegetação em seus territórios é dada por Compans (2001): a valorização da sustentabilidade nas cidades está relacionada justamente à degradação do meio ambiente urbano (poluição sonora e atmosférica, geração de resíduos etc.), que prejudica a qualidade de vida dos habitantes.

Nessas noções de sustentabilidade e de qualidade de vida está embutida a quantificação da vegetação no meio urbano, junto com outros atributos, preferencialmente mensuráveis, como quilômetros de ciclovia implantados ou toneladas de papel recolhidas preservando certo número de árvores (García, 1997). Para a autora, a valorização da linguagem matemática se deve ao fato de ela representar uma "comprovação", uma prova irrefutável da qualidade de vida, devido à influência do discurso da racionalidade técnica.

Às noções de sustentabilidade, qualidade de vida e ecoeficiência ambiental, na agenda neoliberal, são constantemente associados a boa governança e o desenvolvimento econômico (Sánchez, 2001). Mas é com a introdução da noção de competitividade que essa relação entre economia e sustentabilidade ganha mais força. Diniz Filho e Vicentini (2004, p. 133) reiteram que: 
[...] ao mote ambiental, que dá origem às definições de sustentabilidade, alia-se a transferência economicista do termo competitividade, entendendo que as estratégias de desenvolvimento devem pautar-se em progressivos investimentos para a obtenção de melhores índices de qualidade de vida, conforme indicadores internacionais.

No contexto da competição global, a "cidade sustentável" apresenta alguns atributos desejáveis para atrair investimentos (Acselrad, 2001) e, para Domareski-Ruiz (2015), a capacidade crescente de gerar negócios lucrativos de forma sustentável e superior à concorrência determina o que é competitividade. Ainda segundo Domareski-Ruiz (2015), a globalização diferencia e especializa os espaços, de modo que as cidades e os territórios representam fontes de vantagens competitivas, sendo a sustentabilidade elemento fundamental nessa concepção.

Para mostrar essas vantagens competitivas, os governantes têm buscado transformar as cidades em imagem publicitária (Sánchez, 2001), estratégia adotada também por Curitiba, que se destaca nesse quesito. García (1997, p. 107) salienta que:

[...] os projetos urbanísticos dos anos 90 promovidos pelo city marketing reorganizam o espaço metropolitano para adequá-lo às demandas de qualidade de vida urbana e dar-lhe condições de concorrer com outras metrópoles na atração de investimentos e na localização de atividades, sobretudo terciárias.

Exemplo disso é a instalação da fábrica francesa Renault na Região Metropolitana de Curitiba, que, segundo o então governador do Paraná, Jaime Lerner, em reportagem de 29 de março de 1996 da revista Folha de Londrina, citada por García (1997), optou pela região devido, entre outros fatores, à qualidade de vida, "modelo" para o resto do mundo. A atratividade representada pela qualidade de vida curitibana também foi utilizada para incentivar a migração de famílias de executivos vindas de São Paulo e do Rio Janeiro (García, 1997).

Assim, percebe-se a importância de as cidades apresentarem bons panoramas ambientais e de qualidade de vida, preferencialmente mensuráveis, a fim de facilitar para os investidores a comparação entre as cidades para que tenham embasamento para escolher as cidades que apresentem diferenciais para justificar os investimentos.

\section{Considerações finais}

A recomendação de índices mínimos mostrou-se, simultaneamente, fundamental e falha. Fundamental para sintetizar uma informação complexa, de modo que a população possa entender e cobrar das autoridades o valor mínimo de vegetação em sua cidade, bem como para se estabelecer um parâmetro mínimo a ser atingido, desde que baseado em pesquisas e consoante a localidade estudada. Falha porque faltam índices específicos para a realidade das cidades brasileiras, e a indicação de índices acaba se tornando uma medida homogeneizadora e uma meta obrigatória a ser atingida, como a famigerada possível indicação da ONU (de 12 $\mathrm{m}^{2}$ de área verde por habitante), que se tornou o norte de algumas capitais nos planejamentos da vegetação urbana, de maneira que, atingido esse valor, não haveria necessidade de avançar nesse quesito. 
As prefeituras precisam empenhar-se em disponibilizar para a população dados claros e completos sobre a situação da cobertura vegetal das cidades. Muitas capitais não disponibilizam on-line a quantificação de cobertura vegetal ou áreas verdes de seu território, e, entre as que o fizeram, muitas anunciam apenas o número, não aprofundando questões igualmente relevantes como o critério adotado, como foi feito o levantamento, como se distribui essa vegetação na cidade, se há adequação entre as espécies utilizadas e infraestrutura urbana, se são espécies compatíveis com as condições ambientais da cidade etc.

A competição entre cidades, na qual a sustentabilidade e a qualidade de vida proporcionada pelo meio ambiente urbano são elementos fundamentais, não é passível de ser ignorada no mundo capitalista globalizado, em que as cidades precisam competir entre si para atrair investimentos. Porém, talvez fosse possível substituir a matemática como prova da boa qualidade de vida por um planejamento voltado à ecologia e uma boa avaliação apresentada pela população.

Mais importante que buscar aumentar apenas matematicamente o índice de cobertura vegetal a qualquer custo seria elaborar e seguir um planejamento consistente que vise à conservação, ao manejo e à restauração das paisagens urbanas, mediando os conflitos entre os usos propostos para a área e a capacidade da natureza de suportá-los, bem como evitando a redução de áreas naturais e impermeabilizações desnecessárias.

\section{Referências}

ACSELRAD, H. Sentidos da sustentabilidade urbana. In: ACSELRAD, H. (Org.). A duração das cidades: sustentabilidade e risco nas políticas urbanas. Rio de Janeiro: DPEA, 2001. p. 27-55.

BRASIL. INSTITUTO BRASILEIRO DE GEOGRAFIA E ESTATÍSTICA. Cidades. 2016.

Disponível em: http://www.cidades.ibge.gov.br/xtras/home.php. Acesso em: 7 jun. 2016.

BRASIL. INSTITUTO BRASILEIRO DE GEOGRAFIA E ESTATÍSTICA. Mapa de clima do Brasil. Brasilia: IBGE, 2002. Escala 1:5.000.000.

BUCCHERI FILHO, A. T.; NUCCI, J. C. Espaços livres, áreas verdes e cobertura vegetal no bairro Alto da XV, Curitiba-PR. Revista do Departamento de Geografia, São Paulo, v. 18, p. 48-59, 2006.

CAPITAL Ecológica III. Curitiba, 2003. 1 videocassete (27 min), sonoro, color. VHS NTSC. CAVALHEIRO, F. O planejamento de espaços livres: o caso de São Paulo. Revista Silvicultura/Instituto Florestal, São Paulo, v. 16A, parte 3, 1982.

CAVALHEIRO, F; NUCCl, J. C.; GUZZO, P.; ROCHA, Y. T.; Proposição de terminologia para o verde urbano. Boletim Informativo da SBAU (Sociedade Brasileira de Arborização Urbana), Rio de Janeiro, ano VII, n. 3, p. 7, jul./set. 1999.

COMPANS, R. Cidades sustentáveis, cidades globais. Antagonismo ou complementaridade? In: ACSELRAD, H. (Org.). A duração das cidades: sustentabilidade e risco nas políticas urbanas. Rio de Janeiro: DPEA, 2001. p. 105-137 
CURITIBA é escolhida a cidade mais verde entre 17 outras da América Latina. Folha de S.Paulo, 22 nov. 2010. Disponível em: http://wwwl.folha.uol.com.br/ ambiente/834045-curitiba-e-escolhida-a-cidade-mais-verde-entre-17-outras-da-america-latina.shtml. Acesso em: 14 mar. 2017.

DALBEM, R. P.; NUCCI, J. C. Cobertura vegetal: conceituação, classificação e quantificação aplicadas ao bairro São Braz, município de Curitiba-PR. In: SEMINÁRIO LATINO-AMERICANO DE GEOGRAFIA FÍSICA, 4., 2006, Maringá-PR. Anais... Maringá: UEM, 2006.

DESTINO Brasil: João Pessoa, a 2a cidade mais verde do mundo. Catraca Livre, 6 jan. 2014. Disponível em: https://viagem.catracalivre.com.br/brasil/roteiro-viagem/indicacao/destino-brasil-joao-pessoa-a-2a-cidade-mais-verde-do-mundo/. Acesso em: 14 mar. 2017.

DINIZ FILHO, L. L.; VICENTINI, Y. Teorias espaciais contemporâneas: conceito de competitividade sistêmica e o paradigma da sustentabilidade ambiental. In: MENDONÇA, F. (Org.).

Impactos socioambientais urbanos. Curitiba: Editora UFPR, 2004. p. 107-116.

DOMARESKI-RUIZ, T. C. A dinâmica evolutiva da competitividade do destino turístico Curitiba. Tese (Doutorado em Geografia) - Setor de Ciências da Terra, Universidade Federal do Paraná, Curitiba, 2015.

DUBAI já descobre o lado menos fascinante do crescimento. Veja, 30 out. 2010. Disponível em: http://veja.abril.com.br/ciencia/dubai-ja-descobre-o-lado-menos-fascinante-do-crescimento/. Acesso em: 15 set. 2016.

FIGUEIRÓ, A. S. Biogeografia: dinâmicas e transformações da natureza. São Paulo: Oficina de Textos, 2015.

GARCÍA, F. E. S. Cidade espetáculo: política, planejamento e city marketing. Curitiba: Palavra, 1997.

GOIÂNIA. Prefeitura do Município de Goiânia. Plano Diretor de Arborização Urbana de Goiânia. Disponível em: http://www.goiania.go.gov.br/download/amma/relatorio_Plano_Diretor.pdf. Acesso em: 6 abr. 2015.

GOUVÊA, L. A. Biocidade: conceitos e critérios para um desenho ambiental urbano, em localidades de clima tropical de planalto. São Paulo: Nobel, 2002.

GRISE, M. M.; BIONDI, D.; ARAKI, H. A floresta urbana da cidade de Curitiba-PR. Floresta, Curitiba, v. 46, n. 4, p. 425-438, out./dez. 2016.

HORA, C. E. P.; MEDEIROS, F. A. C.; CAPISTRANO, L. F. D. (Org.). Anuário Natal 2013. Natal: Semurb, 2013.

HOUGH, M. Naturaleza y ciudad: planificación urbana y procesos ecologicos. Barcelona: Gustavo Gili, 1998.

ÍNDICE de área verde passa para 64,5 $\mathrm{m}^{2}$ por habitante. Agência de Notícias da Prefeitura de Curitiba, 16 jan. 2012. Disponível em: http://www.curitiba.pr.gov.br/noticias/ indice-de-area-verde-passa-para-645-m2-por-habitante/25525. Acesso em: 12 set. 2014. 
JOÃO PESSOA. Secretaria de Comunicação Municipal. Vídeo Institucional da Prefeitura Municipal de João Pessoa, 23 abr. 2007. Disponível em: https://www. youtube.com/watch?v=tJ3cxRM7XQs. Acesso em: 30 nov. 2016.

LIMA, A. M. L. P.; CAVALHEIRO, F.; NUCCI, J. C.; SOUSA, M. A. L. B.; FIALHO, N. O.; DEL PICCHIA, P. C. D. Problemas de utilização na conceituação de termos como espaços livres, áreas verdes e correlatos. In: CONGRESSO BRASILEIRO DE ARBORIZAÇÃO URBANA, 2., 1994, São Luís. Anais... São Luís, 1994. p. 539-553.

LOMBARDO, M. A. Ilha de calor nas metrópoles: o exemplo de São Paulo. São Paulo: Hucitec, 1985.

MARINGÁ. Observatório Maringá. Programa Cidades Sustentáveis. Disponível em: http://www2.maringa.pr.gov.br/conferencia/?cod=cidadesustentaveis. Acesso em: 14 mar. 2017.

MARTIN, C. A. Landscape Sustainability in a Sonoran Desert City. Cities and the Environment, v. 1, n. 2, 2008.

MARTINS JÚNIOR, O. P. Uma cidade ecologicamente correta. Goiânia: AB, 1996.

MASCARÓ, L. Ambiência urbana. Porto Alegre: Luzzatto, 1996.

MAYMONE, G. Campo Grande ultrapassa Goiânia e se torna a capital mais arborizada. Correio do Estado, Campo Grande, 12 set. 2012. Disponível em: http://www.correiodoestado.com.br/noticias/campo-grande-ultrapassa-goiania-e-se-torna-a-capital-mais-arborizada/159970/. Acesso em: 14 mar. 2017.

MOURA, A. R.; NUCCl, J. C. Cobertura vegetal em áreas urbanas: o caso do bairro de Santa Felicidade, Curitiba-PR. Geografia, Ensino \& Pesquisa, Santa Maria-RS, v. 12, p. 1682-1698, 2008.

MOURA, A. R.; NUCCI, J. C. Análise da cobertura vegetal do bairro de Santa Felicidade, Curitiba-PR. In: SIMPÓSIO BRASILEIRO DE GEOGRAFIA FÍSICA APLICADA, 11., 2005, São Paulo. Anais...São Paulo: USP, 2005. p. 328-339.

NG, E.; CHEN, L.; WANG, Y.; YUAN, C. A study on the cooling effects of greening in a high-density city: An experience from Hong Kong. Building and Environment, v. 47, p. 256-271, 2012.

NOWAK, D. J.; ROWNTREE, R. A.; McPHERSON, E. G.; SISINNI, S. M.; KIRKMANN, E. R.; STEVENS, J. C. Measuring and analyzing urban tree cover. Landscape and Urban Planning, n. 36, p. 49-57, 1996. Disponível em: www.elsevier.com/locate/ landurbplan. Acesso em: 20 maio 2006.

$\mathrm{NUCCl}$, J. C. Qualidade ambiental e adensamento urbano: um estudo de ecologia e planejamento da paisagem aplicado ao distrito de Santa Cecilia (MSP). Curitiba: Edição do Autor, 2008. e-book. Disponível em: www.geografia.ufpr.br/laboratorios/labs. Acesso em: 29 jan. 2012. 
NUCCI, J. C.; CAVALHEIRO, F. Cobertura vegetal em áreas urbanas: conceito e método. GEOUSP, São Paulo, n. 6, p. 29-36, 1999.

NUCCI, J. C.; KROKER, R.; SCHMIDT, E.; BUCCHERI FILHO, A. T. Mapeamento da qualidade ambiental urbana. In: INTERNATIONAL CONGRESS ON ENVIRONMENTAL PLANNING AND MANAGEMENT - ENVIRONMENTAL CHALLENGES OF URBANIZATION, 2005, Brasilia. Anais... Brasilia: PUC, 2005. p. $1-20$.

NUCCI, J. C.; WESTPHALEN, L. A.; BUCCHERI FILHO, A. T.; NEVES, D. L.; OLIVEIRA, F. A. H. D.; KROKER, R. Cobertura vegetal no bairro Centro de Curitiba/PR. GeoUERJ, Rio de Janeiro, p. 1-14, 2003.

OSBORN, L. Hottest Canadian Cities. Current Results, 2016. Disponível em: https:// www.currentresults.com/Weather-Extremes/Canada/hottest-cities.php. Acesso em: 15 dez. 2016.

PARK, B. J.; TSUNETSUGU, Y.; KASETANI, T.; KAGAWA, T.; MIYAZAKI, Y. The physiological effects of Shinrin-yoku (taking in the forest atmosphere or forest bathing): evidence from field experiments in 24 forests across Japan. Environmental Health and Preventive Medicine, v. 15, n. 1, p. 18-26, 2010.

PIVETTA, A.; CARVAlHO, J. A.; DAlBEM, R. P.; MOURA, A. R.; NUCCI, J. C. Sistema de classificação da cobertura do solo para fins de comparação entre cidades e bairros. In: SIMPÓSIO BRASILEIRO DE GEOGRAFIA FÍSICA APLICADA, 11., 2005, São Paulo. Anais... São Paulo: USP, 2005. p. 381-392.

PNUMA. Perspectivas del medio ambiente: América Latina y el Caribe. Panama City: PNUMA, 2010. Disponível em: http://www.pnuma.org/geociudades/PDFs/Manual\%20GEO\%20Ciudades.pdf. Acesso em: 21 out. 2016.

PNUMA. Metodología para la elaboración de los informes GEO Ciudades. Ciudad de México: Pnuma, 2003. Disponível em: http://www.pnuma.org/geo/geoalc3/ Doc\%20COMPLETO/GEO\%20ALC\%203\%20WEB\%20VERSION\%20C.pdf. Acesso em: 21 out. 2016. [parei aqui]

PORTAL DO SERVIDOR. Goiânia é a segunda cidade mais arborizada do mundo. 2014. Disponível em: http://www.portaldoservidor.go.gov.br/post/ver/184337/goiania-e-a-segunda-cidade-mais-arborizada-do-mundo. Acesso em: 14 mar. 2017.

PORTO ALEGRE. Prefeitura Municipal de Porto Alegre. Áreas Verdes. 2006. Disponível em: http://www2.portoalegre.rs.gov.br/smam/default.php?p_secao=283. Acesso em: 13 set. 2016.

RIO DE JANEIRO. Diretoria de informações da cidade - Gerência de Cartografia. Mapa de uso do solo. Rio de Janeiro: DIC, 2015. Escala 1:200.000.

ROCHA, M. F. Cobertura vegetal na região central das capitais brasileiras. 2017. No prelo. 
SÁNCHEZ, F. A (in)sustentabilidade das cidades-vitrine. In: ACSELRAD, H. (Org.). A duração das cidades: sustentabilidade e risco nas políticas urbanas. Rio de Janeiro: DPEA, 2001. p. 171-192

SÃO PAULO. Secretaria Municipal do Verde e do Meio Ambiente. Verde e Meio Ambiente Indicadores (arquivo Excel). Disponível em: http://www.prefeitura.sp.gov. $\mathrm{br} /$ cidade/secretarias/upload/planejamento/arquivos/verde\%20e\%20meio\%20ambiente\%20indicadores.xls. Acesso em: 13 set. 2016.

SEPE, P. M.; GOMES, S. Indicadores ambientais e gestão urbana: desafios para a construção da sustentabilidade na cidade de São Paulo. São Paulo: Secretaria Municipal do Verde e do Meio Ambiente/Centro de Estudos da Metrópole, 2008.

SUKOPP, H.; WERNER, P. Naturaleza en las ciudades: desarrollo de flora y fauna en áreas urbanas. Monografias de la Secretaria de Estado para las Políticas del Agua y el Medio Ambiente. Madrid: Ministério de Obras Públicas y Transportes (MOPT), 1991.

SUTTER, J. D. Vegas tries to kick its water addiction. CNN - Defining America, 2 set. 2011. Disponível em: http://edition.cnn.com/2011/US/09/02/las.vegas.water/. Acesso em: 15 set. 2016.

TOLEDO, F. S.; SANTOS, D. G. Um índice de áreas verdes para a cidade de Uberlândia-MG. In: SANTOS, D. G.; NUCCI, J. C. (Org.). Paisagens geográficas: um tributo a Felisberto Cavalheiro. Campo Mourão, PR: Ed. Fecilcam, 2009.

WOOLLEY, H. Urban open spaces. London: Spon, 2003.

YOUNAN, D.; TUVBLAD, C.; LI, L.; WU, J.; LURMANN, F; FRANKLIN, M.; BERHANE, K.; McCONNELL, R.; WU, A. H.; BAKER, L. A.; CHEN, J. C. Environmental determinants of aggression in adolescents: role of urban neighborhood greenspace.

Child E Adolescent Psychiatry, New York, v. 55, n. 7, p. 591-601, jul. 2016. 